\title{
Calculating optimal surveillance for detection of von Hippel- Lindau-related manifestations
}

\author{
Roeliene C Kruizinga', Wim J Sluiter ${ }^{2}$, Elisabeth G E de Vries', Bernard A Zonnenberg ${ }^{3}$, \\ Cornelis J Lips ${ }^{3}$, Anouk N A van der Horst-Schrivers ${ }^{2}$, Annemiek M E Walenkamp ${ }^{1}$ \\ and Thera $\mathrm{P}$ Links ${ }^{2}$ \\ Departments of ${ }^{1}$ Medical Oncology ${ }^{2}$ Endocrinology, University Medical Center Groningen, University of Groningen, \\ PO Box 30.001, 9700 RB Groningen, The Netherlands \\ ${ }^{3}$ Department of Internal Medicine, University Medical Center Utrecht, Utrecht, The Netherlands
}

Correspondence should be addressed to T P Links

Email

t.p.links@umcg.nl

\begin{abstract}
von Hippel-Lindau (VHL) mutation carriers develop benign and malignant tumors, requiring regular surveillance. The aim of this study was to calculate the optimal organ-specific age to initiate surveillance and optimal intervals to detect initial and subsequent VHL-related manifestations. In this study, we compare these results with the current VHL surveillance guidelines. We collected data from $82 \mathrm{VHL}$ mutation carriers in the Dutch VHL surveillance program. The cumulative proportion of carriers diagnosed with a first VHL-related manifestation was estimated by the Kaplan-Meier method. The Poisson distribution model was used to calculate average time to detection of the first VHL-related manifestation and subsequent manifestations. We used this to calculate the optimal organ-specific age to initiate surveillance and the surveillance interval that results in a detection probability of $5 \%$. The calculated organ-specific ages to initiate surveillance were 0 years (birth) for adrenal glands, 7 years for the retina, 14 years for the cerebellum, 15 years for the spinal cord, 16 years for pancreas, and 18 years for the kidneys. The calculated surveillance intervals were 4 years for the adrenal glands, biennially for the retina and pancreas, and annually for the cerebellum, spinal cord, and kidneys. Compared with current VHL guidelines, the calculated starting age of surveillance was 6 years later for the retina and 5 years earlier for adrenal glands. The surveillance intervals were two times longer for the retina and four times longer for the adrenal glands. To attain a $5 \%$ detection probability rate per organ, our mathematical model indicates that several modifications of current VHL surveillance guidelines should be considered.
\end{abstract}

\section{Key Words}

$\checkmark \mathrm{VHL}$

- von Hippel-Lindau

- surveillance

- second hit

\section{Introduction}

von Hippel-Lindau (VHL) disease is an autosomal dominant disorder caused by a germline mutation in the VHL gene (Lonser et al. 2003). The estimated incidence of VHL disease is between one in 36000 and one in 85000 newborns, with a penetrance rate of almost $100 \%$ by age 75 years (Poulsen et al. 2010). In 2008, 109 living VHL mutation carriers older than 15 years with VHL disease were identified in The Netherlands (Lammens et al. 2011). 
VHL disease leads to the development of multiple vascularized lesions in the CNS. These CNS lesions include hemangioblastomas in the cerebellum, spinal cord, brain stem, nerve root, and supratentorial region; retinal angiomas; and endolymphatic sac tumors (ELST). Visceral features of VHL disease include renal cysts and renal cell cancers (RCC), pheochromocytomas, pancreatic cysts, and pancreatic neuroendocrine tumors (pNET), as well as epididymal and broad ligament cystadenomas (Lonser et al. 2003, Maher et al. 2011).

VHL phenotypes are classified into two types based on clinical appearance: type 1 and type 2 (2a, 2b, and 2c). Type 1 includes all typical VHL-related manifestations except pheochromocytomas. Type $2 \mathrm{a}$ and $2 \mathrm{~b}$ exhibit the full VHL-related manifestation spectrum with low (2a) and high (2b) risk for RCC, while type 2c carriers develop only pheochromocytoma (Maher et al. 1996). The exact relationship between genotype and phenotype is still unknown (Rechsteiner et al. 2011). Currently, the same surveillance schedules are used for all VHL phenotypes. Based on the occurrence of manifestations and their consequences, all VHL mutation carriers and first-degree relatives with unknown $V H L$ gene status are offered surveillance consisting of regular follow-up visits for each organ involved in VHL disease. Work-up according to the Danish, US, and Dutch VHL surveillance guidelines includes biennial MRI for CNS, MRI/CT/ultrasound scans for visceral organs, and yearly ophthalmologist consultations (Hes \& van der Luijt 2000, Lonser et al. 2003, Poulsen et al. 2010, Lammens et al. 2011, VHL family Alliance 2012). VHL surveillance according to the current Danish and US guidelines reduces VHL-related morbidity and mortality (Maher et al. 1990a,b, Poulsen et al. 2010). However, the age for starting surveillance and the surveillance interval are based on limited evidence (Hes \& van der Luijt 2000, Poulsen et al. 2010, Maher et al. 2011). If the probabilities of developing VHL-related manifestations at various ages could be estimated, this would enable evidence-based decisions to be made on the age to start VHL surveillance and on the subsequent surveillance intervals. The aims of our study were, therefore, to calculate the organ-specific age at which to start surveillance, to calculate the surveillance intervals for detecting the first and subsequent VHL-related manifestations, and to compare these calculations with current VHL surveillance guidelines (Hes \& van der Luijt 2000, Poulsen et al. 2010, Lammens et al. 2011, VHL family Alliance 2012).

We based our approach on Knudson's 'second-hit' hypothesis, which is supported by evidence that
VHL-related RCC and hemangioblastomas occur as a consequence of a mutation in the one healthy $V H L$ gene (Maher et al. 1990a,b). Predictive Poisson distribution models can then be used to express the probability of the detection of a VHL-related manifestation over time (Knudson 2001). The linear regression of this Poisson distribution model can provide a calculated average number of years between a first hit and detection of the first VHL-related manifestation $(\delta)$ and an average number of years between two hits (time between hits, TBH).

\section{Subjects and methods}

\section{Study population}

Eligible individuals for this analysis were VHL mutation carriers who underwent VHL surveillance between 1972 and 2012 at two centers of VHL expertise in The Netherlands: the University Medical Center Groningen and the University Medical Center Utrecht. A VHL mutation carrier was defined as an individual with a genetically confirmed VHL mutation or clinical VHL disease characterized by two or more CNS hemangioblastomas or a CNS hemangioblastoma(s) and visceral lesion(s) or by one typical VHL-related manifestation and a first-degree relative with genetically or clinically confirmed VHL disease (Maher et al. 2011).

Surveillance of $V H L$ mutation carriers was performed according to the standard VHL surveillance guidelines in The Netherlands (www.stoet.nl, VHL working group), including the following surveillance measures. VHL mutation carriers have undergone yearly abdominal ultrasound surveillance at the UMCU since 1985 and at the UMCG since 1990. Biannual surveillance for VHLrelated spinal cord lesions began at both centers between 1991 and 1994. Since 2001, VHL mutation carriers have undergone a biennial MRI scan of the cerebellum and spinal cord, an annual ophthalmologist consultation, and an abdominal ultrasound scan, since 2010 they have undergone an abdominal MRI or ultrasound scan in alternate years. Surveillance intervals were irrespective of detection of new lesions. If a lesion was found to have increased in size, then imaging frequency was increased to 6-month intervals until stable disease was ascertained. If the carriers developed symptoms, interim surveillance examinations or specific imaging was performed. Surveillance for pheochromocytomas was performed annually by means of plasma and/or urinary concentrations of metanephrines (metanephrine and normetanephrine) (de Jong et al. 2007).

Published by Bioscientifica Ltd. 


\section{Data collection procedures}

We collected clinical data on VHL mutation carriers, covering the period 1959-2012, from electronic and written patient records. A computerized registration database is used to store data obtained from standard VHL surveillance; we retrieved all relevant data from this database and transferred those into a separate, anonymous database. The identity of the individuals was protected by unique codes, which were known only by two dedicated data managers. In case of uncertainties with respect to follow-up data, the larger databases could only be checked by the data manager, thereby assuring the protection of individual identity. Therefore, according to Dutch Medical Research Involving Human Subjects Act, no further Institutional Review Board approval was required.

Information on genealogy and on the affected family members of the carriers in the study was derived from reports of the Department of Clinical Genetics. Information obtained directly from individual patient records included date of birth, sex, the inherited or de novo mutation, and the organ-specific date of diagnosis of the first VHL-related manifestation (defined as organ involvement). When biochemical or clinical diagnosis of the manifestation preceded a diagnosis based on imaging reports, these data were used if confirmed during surveillance by ultrasound, CT, or MRI scan. The following manifestations were included: cerebral hemangioblastomas, spinal cord hemangioblastomas, retinal hemangioblastomas, RCC and renal cysts, pheochromocytoma, and pNETs and pancreatic cysts. Renal and pancreatic involvement was defined by its first manifestation, irrespective of pathological diagnosis (tumor or cyst). Data on the onset of renal and pancreatic manifestations of individuals born before 1965 and undergoing surveillance at the UMCG were not included because this group did not undergo abdominal surveillance until 1990. Otherwise, it would have appeared that a delay in detection of VHL-related manifestations had occurred, causing bias in this retrospective study. For additional analysis of the effect of VHL phenotype on the age of onset of VHL-related manifestations, the $V H L$ mutation carriers were grouped according to VHL phenotype (type 1: all manifestations except pheochromocytoma; type $2 \mathrm{a} / \mathrm{b}$ : full spectrum; and type 2c: pheochromocytoma only). Group assignment was based on the relevant literature and on the occurrence of a spectrum of VHL-related manifestations in their kindred or in their own history (Table 1; Nordstrom-O'Brien et al. 2010). Kindreds developing only pheochromocytoma were regarded as type 2c ( 1 family). De novo VHL mutation carriers or VHL mutation carriers having a family history with diagnosis of pheochromocytoma and other VHLrelated manifestations were defined as phenotype $2 \mathrm{a} / \mathrm{b}$. Carriers without diagnosis of pheochromocytoma in their personal or family history were defined as VHL phenotype 1 (Nordstrom-O'Brien et al. 2010).

\section{Statistical analysis}

The aim of our study was not to test a hypothesis but to calculate Poisson parameters for time to detection of the first and subsequent VHL-related manifestations. Consequently, power analysis could not be performed. To indicate the precision of the calculations, we have given the s.e..

Carriers of $V H L$ phenotype 1 were excluded from all analyses for pheochromocytoma onset, as pheochromocytomas are not part of this phenotype. Carriers of $V H L$ phenotype 2c were included for analyses of pheochromocytoma only, as this is their only manifestation.

The cumulative proportion of VHL mutation carriers during the entire life span with regard to age at time of detection of the first VHL-related manifestation was calculated by Kaplan-Meier method. Linear regression analysis of natural logarithm of 1 -cumulative proportion $(\ln (1$-cumulative proportion) ) vs this age was carried out to estimate the average incidence $\kappa$ (the hit rate) of tumor formation from the regression coefficient $(=-\kappa)$. The average time between two hits (TBH) with its s.E. was derived from the inverse of $\kappa$ and its s.e. (Table 2). The average time between a first hit and detection of first VHL-related manifestation $($ delay $=\delta$ ) was assessed from the intercept of the $\ln (1-$ cumulative proportion) with the age axis. The s.e. of $\delta$ was defined by the s.e. around the regression line divided by the regression coefficient $\kappa$. Cumulative proportions below the 5\% level were excluded from the regression analysis because of the sloping edge caused by the variance of the delay. The cumulative proportions above the age of 65 years were also excluded from this analysis to prevent bias caused by mortality of patients.

The optimal age for starting surveillance for each organ was calculated from the time to detection of the first manifestation $(\delta)-2$ s.E., the lower end of the $95 \%$ CI of the estimated mean delay. So a safe lower boundary was established with a negligible risk of a first manifestation below this age of starting surveillance. The age of detection of the first VHL-related manifestation in $V H L$ phenotype 1 carriers and in those with phenotype $2 \mathrm{a} / \mathrm{b}$ were compared with log-rank tests.

Published by Bioscientifica Ltd. 
Table 1 Characteristics of VHL mutation carriers

\begin{tabular}{|c|c|c|c|c|}
\hline Characteristics & No. $(\%)$ & VHL type & $\begin{array}{c}\text { Mean age (years) } \\
\text { at last FU } \\
\text { with range }\end{array}$ & VHL-related manifestations \\
\hline \multicolumn{5}{|l|}{ Sex } \\
\hline Male & $41(50)$ & & & \\
\hline Female & $41(50)$ & & & \\
\hline \multicolumn{5}{|l|}{ Mutation } \\
\hline c. $208 \mathrm{G}>\mathrm{A}$ & $1(1)$ & 1 & 20 & $\mathrm{HBr}$ \\
\hline c. $-213-? .463+? \mathrm{del}$ & $4(5)$ & 1 & $45(38-48)$ & $\mathrm{HBr}, \mathrm{HBC}, \mathrm{HBsc}, \mathrm{RCC}, \mathrm{pNET}, \mathrm{Cr}, \mathrm{Cp}$ \\
\hline$c .241 \mathrm{C}>\mathrm{T}$ & $2(2)$ & $2 \mathrm{a} / \mathrm{b}$ & $47(34-59)$ & $\mathrm{HBr}, \mathrm{HBC}, \mathrm{HBsc}, \mathrm{RCC}, \mathrm{pNET}$, Pheo, $\mathrm{Cr}$ \\
\hline c.259_260-insA & $1(1)$ & 1 & 42 & $\mathrm{HBr}, \mathrm{HBC}, \mathrm{HBsC}, \mathrm{RCC}, \mathrm{Cr}, \mathrm{Cp}$ \\
\hline c. $277 \mathrm{G}>\mathrm{A}$ & $2(2)$ & $2 a / b$ & $48(35-60)$ & $\mathrm{HBr}$, HBsc, Pheo, Cr, Cp \\
\hline c.89c297+ & $25(30)$ & 1 & $40(17-70)$ & $\mathrm{HBr}, \mathrm{HBc}, \mathrm{HBsc}, \mathrm{RCC}, \mathrm{pNET}, \mathrm{Cr}, \mathrm{Cp}$ \\
\hline c. $340+1 \mathrm{G}>\mathrm{A}$ & $1(1)$ & 1 & 32 & $\mathrm{HBr}, \mathrm{HBC}, \mathrm{HBsc}, \mathrm{RCC}, \mathrm{Cr}, \mathrm{Cp}$ \\
\hline c.341-59_341-14del & $2(2)$ & $2 a / b$ & $52(33-67)$ & $\mathrm{HBr}, \mathrm{HBC}, \mathrm{RCC}$, Pheo, $\mathrm{Cr}, \mathrm{Cp}$ \\
\hline c. $358 \mathrm{~A}>\mathrm{G}$ & $1(1)$ & 1 & 15 & HBsc \\
\hline c. $407 T>C$ & $1(1)$ & 1 & 41 & $\mathrm{HBC}, \mathrm{HBsc}, \mathrm{RCC}, \mathrm{Cr}, \mathrm{Cp}$ \\
\hline c. $462 \mathrm{~A}>\mathrm{C}$ & $1(1)$ & $2 a / b$ & 71 & $\mathrm{HBc}$, Pheo, $\mathrm{Cr}$ \\
\hline c. $463+2 T>C$ & $1(1)$ & 1 & 31 & $\mathrm{HBr}, \mathrm{HBC}, \mathrm{HBsc}, \mathrm{RCC}, \mathrm{Cr}$ \\
\hline c. $467 \mathrm{~A}>\mathrm{G}$ & $7(9)$ & $2 c$ & $45(7-88)$ & Pheo, $\mathrm{Cr}(1 \mathrm{x})$ \\
\hline c. $497 T>C$ & $1(1)$ & $2 a / b$ & 27 & PNET, Pheo \\
\hline c. $499 \mathrm{C}>\mathrm{T}$ & $1(1)$ & $2 a / b$ & 43 & $\mathrm{HBr}$, HBsc, RCC, Pheo, Cr \\
\hline c.500G $>A$ & $11(13)$ & $2 a / b$ & $45(21-65)$ & $\mathrm{HBr}, \mathrm{HBc}, \mathrm{HBsc}, \mathrm{RCC}, \mathrm{pNET}, \mathrm{Pheo}, \mathrm{Cr}, \mathrm{Cp}$ \\
\hline c.509T $>A$ & $15(18)$ & $2 a / b$ & $45(16-71)$ & $\mathrm{HBr}, \mathrm{HBc}, \mathrm{HBsc}, \mathrm{RCC}, \mathrm{pNET}, \mathrm{Pheo}, \mathrm{Cr}, \mathrm{Cp}$ \\
\hline c.565delG & $1(1)$ & 1 & 30 & $\mathrm{HBC}, \mathrm{Cr}$ \\
\hline 235 (CAG-TAG) & $1(1)$ & 1 & 63 & $\mathrm{HBr}, \mathrm{HBC}, \mathrm{HBsC}, \mathrm{RCC}, \mathrm{Cr}$ \\
\hline Rearrangement SB & $1(1)$ & 1 & 25 & $\mathrm{HBr}, \mathrm{HBC}, \mathrm{HBsc}, \mathrm{Cr}, \mathrm{Cp}$ \\
\hline Unknown & $1(1)$ & 1 & 44 & $\mathrm{HBr}, \mathrm{HBC}, \mathrm{HBsc}, \mathrm{RCC}, \mathrm{Cr}, \mathrm{Cp}$ \\
\hline Nothing found & $1(1)$ & 1 & 40 & $\mathrm{HBr}, \mathrm{HBC}, \mathrm{Cr}$ \\
\hline \multicolumn{5}{|l|}{ VHL phenotype } \\
\hline Phenotype 1 & $40(49)$ & & & \\
\hline Phenotype $2 \mathrm{a} / \mathrm{b}$ & $35(43)$ & & & \\
\hline Phenotype 2c & $7(9)$ & & & \\
\hline Death (till August 2012) & $7(9)$ & & & \\
\hline Mean FU in years with range & & & $17(0-45)$ & \\
\hline
\end{tabular}

$\mathrm{SB}$, Southern blot; $\mathrm{HBr}$, retinal hemangioblastoma; $\mathrm{HBC}$, cerebellar hemangioblastoma; HBsc, spinal cord hemangioblastoma; RCC, renal cell cancer; pNET, pancreatic neuroendocrine tumor; Pheo, pheochromocytoma; Cr, renal cyst; $\mathrm{Cp}$, pancreatic cyst; FU, follow-up.

The optimal surveillance interval for the detection of subsequent VHL-related manifestations was calculated for the 5,10 , and $20 \%$ proportion level of the $\mathrm{TBH}$, defining the detection probability level roughly. Finally, the optimal VHL surveillance was defined by the 5\% detection proportion to create a safe interval with a negligible risk of overlooking a new manifestation.

The optimal age for stopping surveillance of suspected carriers without known DNA status was defined as a probability of future development of a first VHL-related manifestation of $<5 \%$ and calculated by the cumulative proportions of each organ. We added the cumulative proportions of retina, cerebellum, spinal cord, pancreas, and kidney manifestations during the entire life span to assess the number of affected organs per VHL mutation carrier. For this analysis, the carriers of phenotype 1 and $2 \mathrm{a} / \mathrm{b}$ VHL disease were included. Adrenal gland manifestations were excluded from this analysis to guarantee that the maximum number of affected organs was similar in the two groups. The probability levels were calculated for two subgroups based on VHL phenotypes. Two-sided $P$ values $<0.05$ were designated as statistically significant.

\section{Comparison with VHL surveillance guidelines}

The calculated age to start surveillance was compared with the currently advised starting age as defined by the Danish, Dutch, and US VHL surveillance guidelines (Hes \& van der Luijt 2000, Poulsen et al. 2010, Lammens et al. 2011, VHL family Alliance 2012). In addition, our calculated intervals for 5\% detection probability were compared with the advised screening frequency in these same VHL surveillance guidelines.

Published by Bioscientifica Ltd 
Table 2 Time-to-detection of first and subsequent VHL-related manifestations with calculated age for starting surveillance and surveillance interval in $V H L$ mutation carriers

\begin{tabular}{|c|c|c|c|c|c|c|c|c|}
\hline \multirow{2}{*}{$\begin{array}{l}\text { VHL } \\
\text { manifestation }\end{array}$} & \multirow[b]{2}{*}{$\delta$ (years) } & \multirow[b]{2}{*}{ S.E. of $\delta$} & \multirow[b]{2}{*}{ TBH (years) } & \multirow[b]{2}{*}{ S.E. of TBH } & \multirow{2}{*}{$\begin{array}{c}\text { Starting age } \\
\text { (years) }\end{array}$} & \multicolumn{3}{|c|}{ Interval (years) } \\
\hline & & & & & & $5 \%$ & $10 \%$ & $20 \%$ \\
\hline Adrenal gland & 5.2 & 4.42 & 73.3 & 11.00 & 0 & 3.66 & 7.33 & 14.65 \\
\hline Retina & 12.4 & 2.83 & 39.4 & 4.64 & 6.76 & 1.97 & 3.94 & 7.88 \\
\hline Spinal cord & 20.8 & 2.78 & 26.3 & 4.45 & 15.2 & 1.31 & 2.63 & 5.25 \\
\hline Pancreas & 18.2 & 1.20 & 33.6 & 4.07 & 15.8 & 1.68 & 3.36 & 6.72 \\
\hline Cerebellum & 18.1 & 2.25 & 21.1 & 1.78 & 13.60 & 1.06 & 2.11 & 4.23 \\
\hline Kidney & 23.6 & 2.71 & 11.4 & 1.14 & 18.2 & 0.57 & 1.14 & 2.29 \\
\hline
\end{tabular}

Calculated time between hit and detection of first manifestation $(\delta)$ with S.E., time between hits (TBH) with s.E. Estimated optimal age to start surveillance for detecting the first VHL-related manifestation $(\delta-2$ S.E.) and surveillance intervals for respectively 5,10 , or $20 \%$ probability for detecting subsequent VHL-related manifestations.

\section{Results}

\section{Study population}

We used data from 82 VHL mutation carriers in our study (Fig. 1), which is the majority of the 109 identified Dutch VHL mutation carriers. One male VHL mutation carrier was excluded from the analysis because he declined to undergo VHL surveillance. Characteristics of VHL mutation carriers (41 males and 41 females) are shown in Table 1. They were born between 1923 and 2004 and belonged to 26 kindreds with VHL gene mutations covering all three exons of the $V H L$ gene. One kindred consisted of 23 family members, the others of 1-15 members. The mean follow-up time was 17 years (range 0-45 years). In the entire group, seven VHL mutation carriers died, of which six died due to VHL-related manifestations.

\section{Cumulative proportions and time to first and subsequent manifestations}

At the age of 70 years, $63 \%$ of the VHL mutation carriers were diagnosed with pheochromocytoma, 73\% with retinal angiomas, $77 \%$ with pancreas manifestations, $83 \%$ with spinal cord hemangioblastomas, 94\% with cerebellar hemangioblastoma (Fig. 2A), and 99\% with kidney manifestations (Supplementary Figure 1, see section on supplementary data given at the end of this article).

A linear relationship between $\ln (1$-cumulative proportion) and age at first detection was found for all VHL-related manifestations (Fig. 2B and Supplementary Figure 1). The time between the first hit and the detection of first VHL-related manifestation ranged from 5.2 years for the adrenal glands (s.E. 4.42) to 23.6 years for the kidneys (s.e. 2.71) (Table 2). The age at detection of the first kidney manifestation differed between VHL mutation carriers with phenotype 1 and carriers with phenotype $2 \mathrm{a} / \mathrm{b}(P=0.028$, Supplementary Table 1 , see section on supplementary data given at the end of this article). The TBH ranged from 11.4 years for the kidneys (s.E. 1.14) to 73.3 years for the adrenal glands (s.e. 11.00).

\section{Optimal surveillance for the detection of new VHL-related manifestations}

The optimal age to start VHL surveillance ranged from 0 years for the adrenal glands to 18 years for the kidneys (Table 2). The optimal VHL surveillance interval ranged from 0.57 years for the kidneys to 3.66 years for the adrenal glands (Table 2). Compared with current VHL

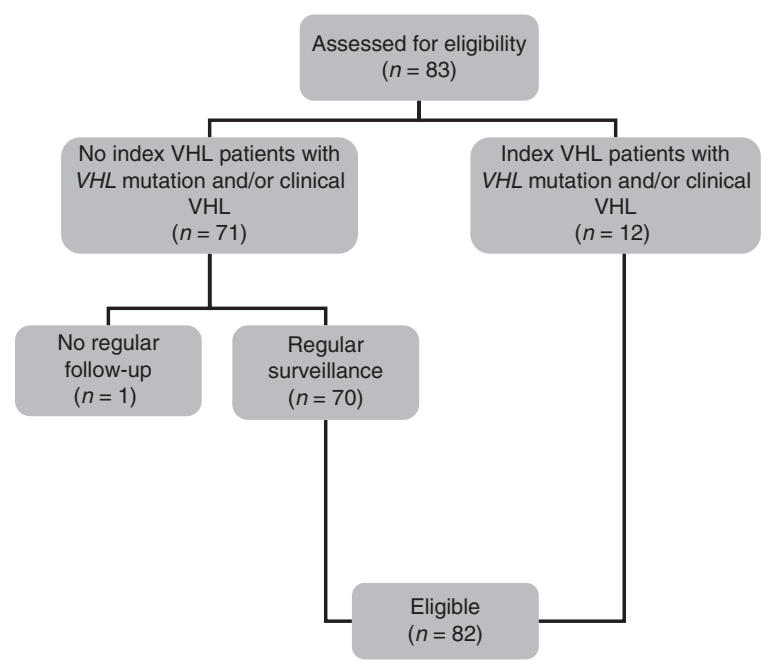

Figure 1

Consolidated Standards of Reporting Trials (CONSORT) diagram.

Published by Bioscientifica Ltd. 

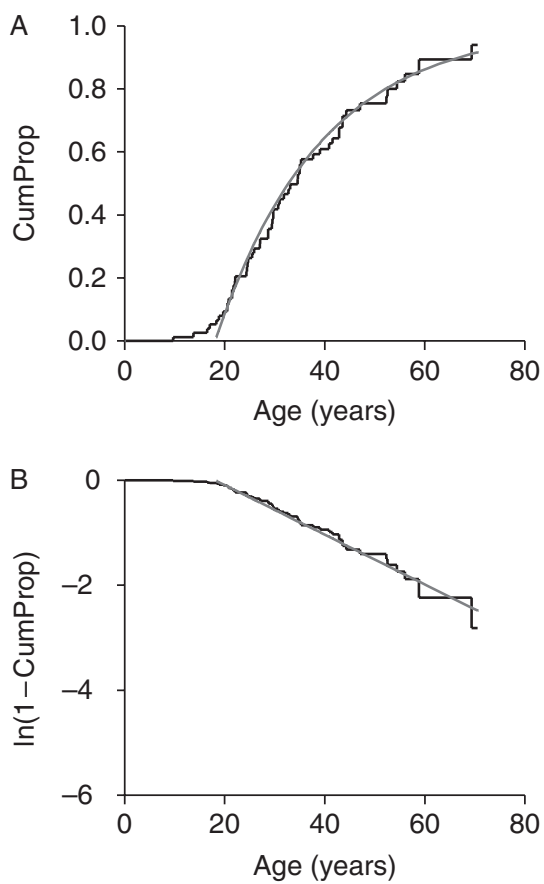

\section{Figure 2}

The cumulative proportion (CumProp) of $V H L$ mutation carriers during entire life span at the time of first cerebellar manifestation, estimated by the Kaplan-Meier method (A); and (B) the natural logarithm of 1 -cumulative proportion ( $\ln (1-$ CumProp $))$. The onset is shown for the studied VHL mutation carriers (black line) and corresponding Poisson distribution model (grey line).

surveillance guidelines in Denmark, The Netherlands, and the USA, the calculated age for starting surveillance was 6 years later for the retina (Hes \& van der Luijt 2000, Poulsen et al. 2010, Lammens et al. 2011, VHL family Alliance 2012), but 5 years earlier for the adrenal gland. Moreover, the calculated surveillance intervals were two times longer for the retina ( 2 years) and four times as long for the adrenal gland (4 years).

\section{Probability of future development of VHL-related manifestations}

According to the total cumulative proportion, four organs on average were affected at the age of 60 years in VHL mutation carriers of phenotypes 1 and $2 \mathrm{a} / \mathrm{b}$ (Fig. 3). We calculated the age after which the probability of future development of a first VHL-related manifestation was $<5 \%$ (Fig. 4). For VHL phenotypes 1 and $2 \mathrm{a} / \mathrm{b}$, we calculated that the probability of developing a first cerebral or spinal cord hemangioblastoma, retinal angioma, kidney cyst or tumor, or pancreatic cyst or tumor was $<5 \%$ after the age of 34 years. For VHL phenotype $2 \mathrm{c}$, the lifelong probability of developing a first pheochromocytoma was above 5\% (Fig. 4).

\section{Discussion}

This is the first study, to our knowledge, that has used Knudson's second-hit hypothesis in VHL mutation carriers to calculate time to detection of the first and subsequent VHL-related manifestations. This mathematical model provides a rationale to define the age at which to start surveillance and subsequent surveillance intervals, at an acceptable detection probability rate per organ. Compared with current Danish, Dutch, and US VHL surveillance guidelines, our calculations showed several deviations for the starting and stopping ages of surveillance for various organs (Hes \& van der Luijt 2000, Poulsen et al. 2010, Lammens et al. 2011, VHL family Alliance 2012).

Surveillance guidelines for VHL will not be influenced by the specific inherited mutation as the second hit is random and is the decisive factor in tumor onset. Surveillance guidelines in hereditary breast cancer and colon cancer and follow-up guidelines for melanoma are based on the probability levels for detecting a tumor at each surveillance visit (Lieberman et al. 2000, U.S. Preventive Services Task Force 2009, Nordstrom-O'Brien et al. 2010, Turner et al. 2011, Pox et al. 2012). These probability levels allow the definition of an acceptable percentage of new tumors that are missed during a defined interval. The surveillance interval is based on the consequences for a patient of a missed diagnosis, and on the sensitivity and specificity of the diagnostic method used.

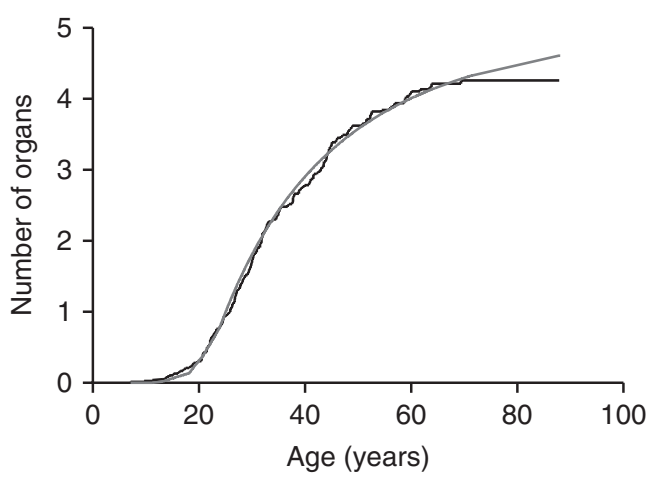

Figure 3

Number of organs (retina, cerebellum, spinal cord, pancreas, and kidneys) affected per $V H L$ mutation carrier during the entire life span. The onset is shown for the studied VHL mutation carriers (black line) and corresponding Poisson distribution model (grey line).

Published by Bioscientifica Ltd. 


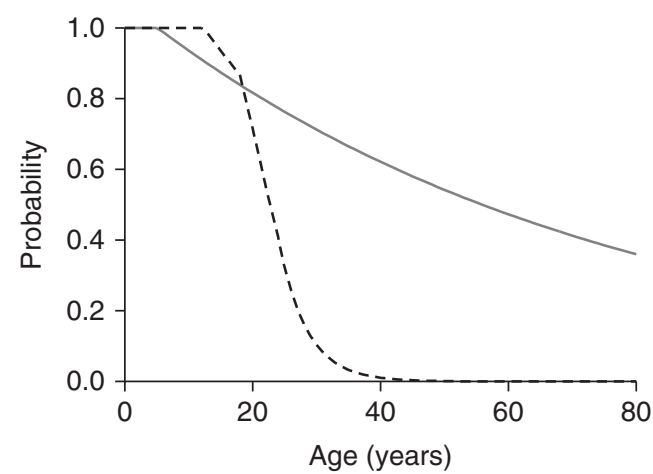

\section{Figure 4}

Probability of future development of a first VHL-related manifestation of the spectrum of $V H L$ phenotype 1 and $2 \mathrm{a} / \mathrm{b}$ (black dashed line) and of $\mathrm{VHL}$ phenotype $2 c$ (grey line) during the entire life span.

Therefore, we also used a pre-set detection probability level for calculating VHL surveillance intervals: the optimal VHL surveillance interval was set at 5\% detection probability. This level is similar to the detection rates for surveillance in breast and colon cancers (Lieberman et al. 2000, U.S. Preventive Services Task Force 2009, Hendrick \& Helvie 2011, Pox et al. 2012). Obviously, all calculated starting ages depend on the sensitivity of the detection methods used; more sensitive techniques could change our calculated age for starting surveillance (Eisenhofer et al. 2011a,b, Timmers et al. 2012).

Due to the substantial deviations from current guidelines in our calculations of the age at which to start surveillance and the subsequent surveillance intervals, we believe that the VHL surveillance guidelines should be adapted, especially for pheochromocytoma and retinal manifestations (Hes \& van der Luijt 2000, Poulsen et al. 2010, Lammens et al. 2011, VHL family Alliance 2012). The current surveillance guidelines recommend starting screening at 1 year of age for the retina, 5 years for the adrenal gland, and 16 years for the kidneys, pancreas, cerebellum, and spinal cord while our analyses support starting at 7 years of age for the retina and at birth for the adrenal gland. More recently, a recommendation for regular ELST surveillance was added to the VHL surveillance guidelines in the USA (VHL family Alliance 2012). These ELST guidelines have not yet been incorporated into the VHL surveillance guidelines for The Netherlands. Therefore, the onset of ELST was not part of our study.

A substantial deviation from current VHL surveillance guidelines concerns our calculated age for starting retinal surveillance in VHL mutation carriers: at the age of 7 years, which is 6 years later than in the guidelines. Our findings are in line with the sparse literature on the onset of
VHL-related retinal angiomas, where detection before the age of 7 years is rarely reported (Singh et al. 2001).

According to our calculations, screening for pheochromocytomas should start at birth. Case reports have been published that describe symptomatic pheochromocytomas before the age of 5 years (Abbott et al. 2006, Sovinz et al. 2010). All these findings support the current hypothesis that symptomatic bilateral pheochromocytoma can actually develop in utero (Weise et al. 2002, Sovinz et al. 2010). Moreover, screening for pheochromocytomas using blood and urine analysis is patient-friendly, sensitive, and relatively cheap (Weise et al. 2002, Eisenhofer et al. 2011a,b).

Current VHL guidelines advise lifelong surveillance for all VHL-related manifestations. In our study, we also calculated the age after which probability of future development of a first VHL-related manifestation is $<5 \%$. This could be used as the age at which to stop surveillance. This is especially of interest for the first-degree relatives of VHL mutation carriers with unknown $V H L$ gene status who are receiving full VHL surveillance and for carriers with unknown phenotype. Additionally, many carriers of type $2 \mathrm{c}$ VHL disease would benefit from a defined age at which to safely stop retinal, cerebellar, spinal cord, kidney, and pancreatic surveillance. Our calculated age for stopping surveillance for individuals at risk for $V H L$ phenotype 1 or $2 \mathrm{a} / \mathrm{b}$ is 34 years. Individuals at risk for $\mathrm{VHL}$ phenotype $2 \mathrm{c}$ require lifelong surveillance for pheochromocytoma. We observed that after 34 years of age, the probability of detecting a first VHL-related manifestation is $<5 \%$, e.g., at the age of 34 years, more than $95 \%$ of VHL patients has developed one or more VHL-related manifestations, suggesting that loss of heterozygosity ( $\mathrm{LOH})$ occurs at a young age, after which tumors grow and become detectable. The young age of pheochromocytoma onset indicates the oncogenic dominant function of the VHL gene (Hes et al. 2003). Causes of LOH of the VHL gene can be either mutation or methylation of the second allele (Crossey et al. 1994, Herman et al. 1994, Prowse et al. 1997, Glasker et al. 2001, Kim \& Kaelin 2004). Moreover, recent studies have shown that mutations or methylation of other vulnerable (flanking) genes also affect the VHL phenotype (Martinez et al. 2000, Gijtenbeek et al. 2002). If future research can shed light on the genotype-phenotype correlation, then an international analysis of a large cohort could establish more individualized surveillance guidelines. Current surveillance schedules are the same for all $V H L$ phenotypes. Reducing the surveillance for RCC in VHL mutation carriers with a low risk for RCC was recently suggested (Nielsen et al. 2011).

Published by Bioscientifica Ltd. 
In our study, we focused on defining the probability of detecting organ involvement instead of malignancy. In general, the therapeutic consequences of diagnosing a malignant tumor differ from the consequences of diagnosing a cyst (Marcos et al. 2002, Charlesworth et al. 2012, Schietke et al. 2012). However, in organs such as the kidney, complex cysts in VHL-related disease can be difficult to distinguish from solid malignancies. Moreover, transition from cysts to carcinoma can occur (Choyke et al. 1992, Poston et al. 1995, Jilg et al. 2012).

We conclude that the age for starting surveillance for VHL-related manifestations should be revised. Based on our calculations, several modifications of current VHL surveillance guidelines can be recommended. Most importantly, surveillance for pheochromocytoma should start at a very young age (in the first year of life), and ophthalmologist consultations for retinal angioma screening should be postponed until the age of 7 years. Further prospective studies are necessary, especially in other geographical populations, before incorporating our findings into guidelines and clinical practice.

\section{Supplementary data}

This is linked to the online version of the paper at http://dx.doi.org/10.1530/ ERC-13-0308.

\section{Declaration of interest}

The authors declare that there is no conflict of interest that could be perceived as prejudicing the impartiality of the research reported.

\section{Funding}

This research was supported by the Jan Kornelis de Cock Stichting and a UEF-JSM Talent grant.

\section{Author contribution statement}

R C Kruizinga, W J Sluiter, T P Links, A M E Walenkamp, and E G E de Vries conceived and designed the study. T P Links, A N A van der Horst-Schrivers, B A Zonnenberg, and C J Lips provided study materials and patients. R C Kruizinga, W J Sluiter, A N A van der Horst-Schrivers, B A Zonnenberg, C J Lips, and T P Links collected and assembled the data. R C Kruizinga, W J Sluiter, T P Links, A M E Walenkamp, and E G E de Vries performed data analysis and interpretation. R C Kruizinga, W J Sluiter, T P Links, A M E Walenkamp, E G E de Vries, A N A van der Horst-Schrivers, B A Zonnenberg, and C J Lips wrote the manuscript. All authors approved the final manuscript.

\section{References}

Abbott MA, Nathanson KL, Nightingale S, Maher ER \& Greenstein RM 2006 The von Hippel-Lindau (VHL) germline mutation V84L manifests as

http://erc.endocrinology-journals.org DOI: 10.1530/ERC-13-0308
(C) 2014 Society for Endocrinology Printed in Great Britain early-onset bilateral pheochromocytoma. American Journal of Medical Genetics. Part A 140 685-690. (doi:10.1002/ajmg.a.31116)

Charlesworth M, Verbeke CS, Falk GA, Walsh M, Smith AM \& Morris-Stiff G 2012 Pancreatic lesions in von Hippel-Lindau disease? A systematic review and meta-synthesis of the literature Journal of Gastrointestinal Surgery 16 1422-1428. (doi:10.1007/s11605-012-1847-0)

Choyke PL, Glenn GM, Walther MM, Zbar B, Weiss GH, Alexander RB, Hayes WS, Long JP, Thakore KN \& Linehan WM 1992 The natural history of renal lesions in von Hippel-Lindau disease: a serial CT study in 28 patients. AJR. American Journal of Roentgenology 159 1229-1234. (doi:10.2214/ajr.159.6.1442389)

Crossey PA, Richards FM, Foster K, Green JS, Prowse A, Latif F, Lerman MI, Zbar B, Affara NA \& Ferguson-Smith MA 1994 Identification of intragenic mutations in the von Hippel-Lindau disease tumour suppressor gene and correlation with disease phenotype. Human Molecular Genetics 3 1303-1308. (doi:10.1093/hmg/3.8.1303)

Eisenhofer G, Lenders JW, Timmers H, Mannelli M, Grebe SK, Hofbauer LC, Bornstein SR, Tiebel O, Adams K, Bratslavsky G et al. 2011a Measurements of plasma methoxytyramine, normetanephrine, and metanephrine as discriminators of different hereditary forms of pheochromocytoma. Clinical Chemistry 57 411-420. (doi:10.1373/ clinchem.2010.153320)

Eisenhofer G, Timmers HJ, Lenders JW, Bornstein SR, Tiebel O, Mannelli M, King KS, Vocke CD, Linehan WM, Bratslavsky G et al. 2011b Age at diagnosis of pheochromocytoma differs according to catecholamine phenotype and tumor location. Journal of Clinical Endocrinology and Metabolism 96 375-384. (doi:10.1210/jc.2010-1588)

Gijtenbeek JM, Jacobs B, Sprenger SH, Eleveld MJ, van Kessel AG, Kros JM, Sciot R, van Calenbergh F, Wesseling P \& Jeuken JW 2002 Analysis of von Hippel-Lindau mutations with comparative genomic hybridization in sporadic and hereditary hemangioblastomas: possible genetic heterogeneity. Journal of Neurosurgery 97 977-982. (doi:10.3171/jns.2002.97.4.0977)

Glasker S, Bender BU, Apel TW, van Velthoven V, Mulligan LM, Zentner J \& Neumann HP 2001 Reconsideration of biallelic inactivation of the VHL tumour suppressor gene in hemangioblastomas of the central nervous system. Journal of Neurology, Neurosurgery, and Psychiatry 70 644-648. (doi:10.1136/jnnp.70.5.644)

Hendrick RE \& Helvie MA 2011 United States Preventive Services Task Force screening mammography recommendations: science ignored. AJR. American Journal of Roentgenology 196 W112-W116. (doi:10.2214/ AJR.10.5609)

Herman JG, Latif F, Weng Y, Lerman MI, Zbar B, Liu S, Samid D, Duan DS, Gnarra JR \& Linehan WM 1994 Silencing of the VHL tumor-suppressor gene by DNA methylation in renal carcinoma. PNAS $919700-9704$. (doi:10.1073/pnas.91.21.9700)

Hes FJ \& van der Luijt RB 2000 von Hippel-Lindau disease: protocols for diagnosis and periodical clinical monitoring. National von Hippel-Lindau disease working group. Nederlands Tijdschrift Voor Geneeskunde 144 505-509.

Hes FJ, Hoppener JW \& Lips CJ 2003 Pheochromocytoma in von Hippel-Lindau disease. Journal of Clinical Endocrinology and Metabolism 88 969-974. (doi:10.1210/jc.2002-021466)

Jilg CA, Neumann HP, Glasker S, Schafer O, Ardelt PU, Schwardt M \& Schultze-Seemann W 2012 Growth kinetics in von Hippel-Lindauassociated renal cell carcinoma. Urologia Internationalis 88 71-78. (doi:10.1159/000333348)

de Jong WH, Graham KS, van der Molen JC, Links TP, Morris MR, Ross HA, de Vries EG \& Kema IP 2007 Plasma free metanephrine measurement using automated online solid-phase extraction HPLC tandem mass spectrometry. Clinical Chemistry 53 1684-1693. (doi:10.1373/ clinchem.2007.087114)

Kim WY \& Kaelin WG 2004 Role of $V H L$ gene mutation in human cancer. Journal of Clinical Oncology 22 4991-5004. (doi:10.1200/JCO.2004. 05.061) 
Knudson AG 2001 Two genetic hits (more or less) to cancer. Nature Reviews. Cancer 1 157-162. (doi:10.1038/35101031)

Lammens CR, Aaronson NK, Hes FJ, Links TP, Zonnenberg BA, Lenders JW, Majoor-Krakauer D, Van Os TA, Gomez-Garcia EB, de Herder W et al. 2011 Compliance with periodic surveillance for von-Hippel-Lindau disease. Genetics in Medicine 13 519-527. (doi:10.1097/GIM. 0b013e3182091a1d)

Lieberman DA, Weiss DG, Bond JH, Ahnen DJ, Garewal H \& Chejfec G 2000 Use of colonoscopy to screen asymptomatic adults for colorectal cancer. Veterans Affairs Cooperative Study Group 380. New England Journal of Medicine 343 162-168. (doi:10.1056/ NEJM200007203430301)

Lonser RR, Glenn GM, Walther M, Chew EY, Libutti SK, Linehan WM \& Oldfield EH 2003 von Hippel-Lindau disease. Lancet 361 2059-2067. (doi:10.1016/S0140-6736(03)13643-4)

Maher ER, Yates JR, Harries R, Benjamin C, Harris R, Moore AT \& Ferguson-Smith MA 1990a Clinical features and natural history of von Hippel-Lindau disease. Quarterly Journal of Medicine 77 1151-1163. (doi:10.1093/qjmed/77.2.1151)

Maher ER, Yates JR \& Ferguson-Smith MA 1990 $b$ Statistical analysis of the two stage mutation model in von Hippel-Lindau disease, and in sporadic cerebellar haemangioblastoma and renal cell carcinoma. Journal of Medical Genetics 27 311-314. (doi:10.1136/jmg.27.5.311)

Maher ER, Webster AR, Richards FM, Green JS, Crossey PA, Payne SJ \& Moore AT 1996 Phenotypic expression in von Hippel-Lindau disease: correlations with germline VHL gene mutations. Journal of Medical Genetics 33 328-332. (doi:10.1136/jmg.33.4.328)

Maher ER, Neumann HP \& Richard S 2011 von Hippel-Lindau disease: a clinical and scientific review. European Journal of Human Genetics 19 617-623. (doi:10.1038/ejhg.2010.175)

Marcos HB, Libutti SK, Alexander HR, Lubensky IA, Bartlett DL, Walther MM, Linehan WM, Glenn GM \& Choyke PL 2002 Neuroendocrine tumors of the pancreas in von Hippel-Lindau disease: spectrum of appearances at CT and MR imaging with histopathologic comparison. Radiology 225 751-758. (doi:10.1148/radiol.2253011297)

Martinez A, Fullwood P, Kondo K, Kishida T, Yao M, Maher ER \& Latif F 2000 Role of chromosome 3p12-p21 tumour suppressor genes in clear cell renal cell carcinoma: analysis of VHL dependent and VHL independent pathways of tumorigenesis. Molecular Pathology $\mathbf{5 3}$ 137-144. (doi:10.1136/mp.53.3.137)

Nielsen SM, Rubinstein WS, Thull DL, Armstrong MJ, Feingold E, Stang MT, Gnarra JR \& Carty SE 2011 Genotype-phenotype correlations of pheochromocytoma in two large von Hippel-Lindau (VHL) type 2A kindreds with different missense mutations. American Journal of Medical Genetics. Part A 155A 168-173. (doi:10.1002/ajmg.a.33760)

Nordstrom-O'Brien M, van der Luijt RB, van Rooijen E, van den Ouweland AM, Majoor-Krakauer DF, Lolkema MP, van Brussel A, Voest EE \& Giles RH 2010 Genetic analysis of von Hippel-Lindau disease. Human Mutation 31 521-537. (doi:10.1002/humu.21219)

Poston CD, Jaffe GS, Lubensky IA, Solomon D, Zbar B, Linehan WM \& Walther MM 1995 Characterization of the renal pathology of a familial form of renal cell carcinoma associated with von Hippel-Lindau disease: clinical and molecular genetic implications. Journal of Urology 153 22-26. (doi:10.1097/00005392-199501000-00009)

Poulsen ML, Budtz-Jorgensen E \& Bisgaard ML 2010 Surveillance in von Hippel-Lindau disease (vHL). Clinical Genetics 77 49-59. (doi:10.1111/ j.1399-0004.2009.01281.x)

Pox CP, Altenhofen L, Brenner H, Theilmeier A, Von Stillfried D \& Schmiegel W 2012 Efficacy of a nationwide screening colonoscopy program for colorectal cancer. Gastroenterology 142 1460-1467.e2. (doi:10.1053/j.gastro.2012.03.022)

Prowse AH, Webster AR, Richards FM, Richard S, Olschwang S, Resche F, Affara NA \& Maher ER 1997 Somatic inactivation of the VHL gene in von Hippel-Lindau disease tumors. American Journal of Human Genetics 60 765-771.

Rechsteiner MP, von Teichman A, Nowicka A, Sulser T, Schraml P \& Moch H 2011 VHL gene mutations and their effects on hypoxia inducible factor HIF $\alpha$ : identification of potential driver and passenger mutations. Cancer Research 71 5500-5511. (doi:10.1158/0008-5472. CAN-11-0757)

Schietke RE, Hackenbeck T, Tran M, Gunther R, Klanke B, Warnecke CL, Knaup KX, Shukla D, Rosenberger C, Koesters R et al. 2012 Renal tubular HIF- $2 \alpha$ expression requires VHL inactivation and causes fibrosis and cysts. PLOS ONE 7 e31034. (doi:10.1371/journal.pone.0031034)

Singh AD, Nouri M, Shields CL, Shields JA \& Smith AF 2001 Retinal capillary hemangioma: a comparison of sporadic cases and cases associated with von Hippel-Lindau disease. Ophthalmology 108 1907-1911. (doi:10.1016/S0161-6420(01)00758-8)

Sovinz P, Urban C, Uhrig S, Stepan V, Lackner H, Schwinger W, Benesch M, Moser A, Spuller E \& Speicher MR 2010 Pheochromocytoma in a 2.75-year-old-girl with a germline von Hippel-Lindau mutation Q164R. American Journal of Medical Genetics. Part A 152A 1752-1755. (doi:10.1002/ajmg.a.33407)

Timmers HJ, Chen CC, Carrasquillo JA, Whatley M, Ling A, Eisenhofer G, King KS, Rao JU, Wesley RA, Adams KT et al. 2012 Staging and functional characterization of pheochromocytoma and paraganglioma by ${ }^{18} \mathrm{~F}$-fluorodeoxyglucose $\left({ }^{18} \mathrm{~F}\right.$-FDG) positron emission tomography. Journal of the National Cancer Institute 104 700-708. (doi:10.1093/jnci/ djs188)

Turner RM, Bell KJ, Morton RL, Hayen A, Francken AB, Howard K, Armstrong B, Thompson JF \& Irwig L 2011 Optimizing the frequency of follow-up visits for patients treated for localized primary cutaneous melanoma. Journal of Clinical Oncology 29 4641-4646. (doi:10.1200/ JCO.2010.34.2956)

U.S. Preventive Services Task Force 2009 Screening for breast cancer: U.S. preventive services task force recommendation statement. Annals of Internal Medicine 151 716-726. (doi:10.7326/0003-4819-151-10200911170-00008)

VHL Family Alliance 2012 The VHL Handbook, What you need to know about VHL. 4th edn, pp 46-51. Boston, MA, USA: VHL Family Alliance.

Weise M, Merke DP, Pacak K, Walther MM \& Eisenhofer G 2002 Utility of plasma free metanephrines for detecting childhood pheochromocytoma. Journal of Clinical Endocrinology and Metabolism 87 1955-1960. (doi:10.1210/jc.87.5.1955)

Received in final form 14 October 2013

Accepted 16 October 2013

Made available online as an Accepted Preprint

16 October 2013 http://erc.endocrinology-journals.org DOI: 10.1530/ERC-13-0308
(C) 2014 Society for Endocrinology Printed in Great Britain
Published by Bioscientifica Ltd. 